\title{
Class Lists, or Dictionary Catalogues?
}

\section{(A Dofouce of the latter, in reply to the papers on Class Lists by Messrs. Jast and Brown.)}

I $\mathrm{N}$ a paper on "The Class List," read before this Association at its Annual Meeting last year, and again in a more recent paper $^{1}$ on "The Compilation of Class Lists," first Mr. Jast, and then Mr. Jast in collaboration with Mr. Brown, have strenuously advocated the superiority of the class list in comparison with the dictionary catalogue. I am perfectly certain that the writers were in both instances actuated by a desire to say something that should lead to an improvement in the quality of common cataloguing - by which term I mean the usual method of cataloguing books in, say, the lending departments of our public libraries. I am assured that with such an object we shall all sympathise; but, at the same time, I imagine that from several of their claims and statements many of us will strongly dissent. It is because I am of opinion that they have declared themselves too dogmatically; that they have been intolerant of the dictionary system even to the point of absolute unfairness; and, still more, because time permitted no adequate discussion upon the latter paper, that I introduce the subject again, regarding it from another point of view.

Addison tells us that when Will Wimble and Tom Touchy referred a delicate point of difference to Sir Roger de Coverley, that worthy knight decided that " much might be said on both sides." It appears to me that no other view than this can properly be taken with regard to our new "battle of the books." But this aspect apparently escaped Messrs. Brown and Jast, who betray the cause of their fall by confessing that in the writing of their paper they were " animated largely by the determination to be emphatic enough and aggressive enough to arouse interest, even though they raise antagonism at the same time." This 
somewhat Jesuitical policy has, I think, answered expectations; but it has led its authors into rash statements, and into criticisms which might be construed as covering personal bias had we not known its authors better. The manner in which they handled dictionary catalogues was, to my mind, suggestive of nothing so much as of freebooters rushing out of ambush upon their unsuspecting victims, much as Prescott relates of the Spanish nobles of old.

My first point of divergence from them is that much of their criticism was beside the mark, for they painted only the glories of the class list, and the defects-not even of the dictionary system, but - of certain dictionary catalogues. It is such an obvious fact that I must apologise for mentioning it, that a system may be good and at the same time examples of it may bo bad. The proof that a clergyman is a rogue is no proof that his creed is wrong. Nor, by the same rule, would the exhibition of any number of mistakes in practice prove that the system of dictionary cataloguing is either defective or inferior to any other system. The superiority of the class guide, if it exist at all, must be proved by other means than this. The injustice of such a contrast has already elicitod from Mr. Ogle a defence of his own catalogue; and Mr. Ogle states the real case very neatly when be says that he would like to see a fair comparison between a class list such as Mr. Brown has made, and a dictionary catalogue, dealing with the same books, such as he coutd make if he set about it. As this comparison is at present impossible, I propose to compare the excellent class guides of Clerkenwell and Peterborough with the equally excellent dictionary catalogue which Mr. Goss has compiled for Lewisham.

But before instituting this comparison, let us examine, very briefly, the excellencies (real and alleged) of the class list. I am not a partisan in this matter, and willingly admit that the class list form of cataloguing has advantages which the dictionary system does not share. Let me hasten to add, however, that I claim as much on behalf of dictionary cataloguing.

It is undoubtedly an advantage, so far as it goes, that the publication of class lists does away with the necessity of waiting until all the books in the library are acquired, much less catalogued, before printing a list. By adopting this system the librarian may build up and catalogue his library by one section at a time, a course which is obviously impossible if a dictionary catalogue is contemplated. But is this advantage substantial, 
after all ? If the religious or philosophical section is first dealt with, and-for sake of argument-history last, I question whether historical readers would be quicker served than by the issue of a complete dictionary catalogue. And something must be last. No doubt the more popular depatments of literature would be dealt with first; but I observe that it is usual to group several sections together in class lists, and this discounts the rapidity of publication. Whether the entire library would be more quickly catalogued by class guides or by one dictionary catalogue is perhaps open to a difference of opinion, but I opine that the latter plan would be the quicker one.

But now I come to a more solid advantage, for there can be little doubt that the compilation of class guides would almost always permit the expenditure of relatively more time to their preparation than is usually the case with larger catalogues. Most catalogues are, I suppose, prepared in haste, and hurried through the press. Especially is this so with regard to new libraries, the catalogues of which should be tenderly treated by reviewers. A class guide comes in as a convenient stop-gap here; and when the Marylebone Library opened, eight years ago, this plan was by stress of circumstances forced upon me. In that particular instance the class guide appeared in weekly sections in a local paper, the oditor of which was good enough to treat the matter as news-though not to the extent of paying for it. I mention this, firstly, as a hint for others, and secondly to confess that I do not pretend to draw any conclusions as to the merits of class lists from this short and imperfect experience.

Another advantage claimed for class lists is that a borrower can purchase at a smaller cost that portion of the catalogue which interests him, instead of paying more for a larger list which contains much that he does not want. But this assumes, $2 s$ does the whole system of class guides, that library readers are specialists, and I cannot concur in this conclusion. I have not noticed in my career that any appreciable proportion of borrowers are of this character, although there may be, and probably are, some such persons (exclusive of the specialist in fiction) at most libraries. I put it to my fellow librarians whether they find most of their readers, in the lending library, pursuing a course of study in any one branch of knowledge ? Students we have, of course, and also not infrequently persons in search of information on scientific or other subjects. And these serious readers we should provide for in our catalogues. If thoy exist in eny 
number I should not hesitate to issue class guides for their benefit; and this might well be done with regard to such literature, in all departments of the library, as relates to a dominant local industry. But with these exceptions-which should be additional to the general catalogue-I hope to show that a good dictionary catalogue is capable of meeting all the demands likely to be made upon it. If it does not do this a reference to the librarian would supply the required information. Unless the assumption that lending library borrowers are specialists is made good, the main argument for class guides falls to the ground. An advantage which might more fairly be claimed for the latter is that they are more convenient in size than most dictionary catalogues.

In their collaborated paper, Messrs. Brown and Jast state that the cost of a dictionary catalogue is out of all proportion to its actual value to readers, in comparison with the class guide. This presumably means that the dictionary catalogue is vastly more costly than class guides; and, consequently, that they have discovered a reliable basis of calculation. The form and cost of producing dictionary catalogues is so varied that one must congratulate them upon the accomplishment of so difficult a feat. In proof of their statement, they mention the case of a certain library which in 1889 issued a general catalogue at a cost of $\ell^{160}$ for 5,000 copies. Five years later a new catalogue was required. What was to be done? By issuing a catalogue in the form of four class lists with some omissions, $£$ 100 was saved! Such an economy gives us "pause." It is too valuable a hint to be lost. Yet before accepting it as a brilliant proof of superiority over the dictionary catalogue, one would like to know what the omissions amounted to, and whether the same omissions could not have been made in a dictionary catalogue; whether the paper and ink were of the same quality in both cases, whether the type was set similarly in each case, or if one was not more solid than the other; whether the same number of copies were "struck off" throughout; and, finally, whether the printing contract was not in the latter instance more favourably placed than in the formor. I assume that the class guides would be paper bound, whilst the dictionary catalogues would be bound in boards.

So much for the claims of the class guides. Their potentialities may be as enormous as Mr. Jast thinks; but until they are reduced to a more concrete form it is difficult to discuss their merits. 
As I have stated before, one part of Messrs. Brown and Jast's paper was devoted to the apotheosis of the class list, the other to destructive criticism of dictionary catalogues. I have dealt fairly, I think, with the former, and now turn to the latter. We have seen the obverse side of the medal; now let us look at the reverse.

Complaint was made in their paper of "wild and weird" statements by the author of "Some Pitfalls in Cataloguing." I shall leave that gentleman to defend himself--which he is well able to do. But $I$ will venture to draw your attention to the extremely " wild and weird " criticism of the critics. Here is an instance:- " Every dictionary catalogue that ever was is full of inconsistencies, and reduces enquirers to the necessity of hunting all over the alphabet in order to ascertain what the library has on any given topic. Then, again, as in all dictionary catalogues, no clue is given to the ground covered by the books, beyond what the often vague title has to tell us." I am at a loss to understand how two such able men could possibly shut out all hope of escape by making statements such as these. Such unguarded generalisations are enough to spoil any case, and in this instance the writers completely throw their argument away. The fault of inconsistency must be admitted, but it applies to all kinds of cataloguing. Few things, perhaps, are more difficult than consistency in classification and cataloguing. But how will they attempt to justify the other portions of their criticism ? Many of the dictionary catalogues recently compiled afford visible proof that the reader has not to hunt wearily through the full alphabet of author and title entries to find out what the library contains upon a given topic. Some of the very catalogues held up to derision prove this point against the deriders. The Bootle catalogue is really an author and subject list, with title entries for works of fiction. Books are thus gathered together under their subject headings, whilst cross-references from one heading to another completes the information. Another catalogue held to scorn has subject headings treated in the same scientific manner; and it would be possible, were it necessary, to mention others having this useful trait.

As to the statement that no dictionary catalogues afford a clue, beyond their titles, to the contents of books, a sufficient answer will be found in the fact that a brilliant exception to the general rule will be found in the catalogue of the Lewisham (Perry Hill) Branch Library-a dictionary catalogue which shows, in 
a sufficiently obvious manner, that many of the features so eulogised in connection with the class list may be incorporated with equal facility in its rival.

The appendix with which Messrs. Brown and Jast concluded their paper affords an interesting study in preferences-I had almost said in prejudice. I also have an appendix. ${ }^{x}$ For this purpose I have taken the same section, relating to books on Spain, as was given before. The class guide entries are reprinted without alteration, and they are a distinct improvement upon the threadbare style of old. But in place of the dictionary catalogue entries I have selected a more modern example, taken from the Lewisham catalogue; and to this comparison I invite your attention. Here we have an extract from a modern class guide, and another, on the same subject, from a modern catalogue. They are both good, the same idea prevails in both, and it proves my point that the excellencies of the class guide may be applied with equal success to the dictionary system. The Bootle catalogue divides its Spanish items into seven groups, and these might with advantage have been selected for comparison in the paper on the "Compilation of the Class List." As to the value of annotations there can scarcely be two opinions, but the thing must be well done, or not at all. Here is a legitimate opening for the librarian to display himself, for concise and correct annotations are not always easy of attainment. According to Cutter's rules, these should be "brief and pointed." If I may venture a hint, I should say that annotations should never convey the cataloguer's personal opinion as to the merits of the book under notice.

In the class guide we have subjects together and author lists shattered into fragments. Ruskin's works, for instance, might be scattered into half-a-dozen separate lists, and the unfortunate individual who wished to indulge in a course of study in Ruskin would, perforce, be compelled to hunt through the index of each list, and wearily turn from page to page, and section to section, to discover all the references. And how many other authors would have to be similarly dissected in these days of versatile genius and voluminous writing ? To fight the class-list champions with their own weapons: Do not readers attach themselves as much to authors as to subjects? And if the class list has the advantage in treatment of subjects, the dictionary catalogue goes one better in respect of authors. But I contend that a good

'The appendix will be found at the end of this paper. 
dictionary catalogue not only enjoys this latter advantage, but, if the subject entries are worked out as patiently as in the class guides of Messrs. Brown and Jast (not to mention others), that it equals the class guide in this particular and excels it in the other.

I regard it as an advantage that in a general catalogue books of all classes jostle together. It is not only that the otherwise solid character of the page is likely to frighten unsettled readers to the fiction list; but also that-at least one would fain hope itby this jostling together of various classes of literature readers are sometimes induced to enlarge the circle of their reading. Personally ${ }_{k}$ I entertain a doubt as to the wisdom of issuing separate fiction lists, in view of the fact that our critics are so severe upon the percentage of fiction issued from libraries. On this point, however, I speak with diffidence. Only those who have had experience are qualified to express an opinion of weight on the matter, and this experience I do not possess. It would be instructive to know the relative sales of the various class lists where the experiment has been tried. Of course it may be urged, in reply, that the people who pay the piper have the right to call the tune; but into neither the ethics of this question nor into the alluring and well-worn subject of fiction issue do I now propose to enter.

How, then, does the question stand ? Are class guides better than dictionary catalogues; or are dictionary catalogues better than class guides; or is there no case between them? Let us not judge it upon false issues. Messrs. Brown and Jast have (innocently enough, no doubt) compared their own model guides with old forms of dictionary catalogues. They dealt too largely with specific examples, and too little with systems. It must bo admitted that in so far as class lists can be prepared quickly, revised rapidly, and printed off in small editions at a small cost, they enjoy an advantage which their rival cannot claim. But I think their advantages stop here. Without any desiro to disparage a system which I should be quick to adopt if I thought it advantageous so to do, I hold that the dictionary catalogue is the better one for a londing library. I am not here to defend-nor to contemn-an attenuated system of bald author and title entries, to which we have been accustomed, but which has been dying out for somo years past. A good dictionary catalogue should heve subject entries very carefully treated. Title entries may be reduced, and often discarded, to reduce the cost-as was done in the Bootle catalogue. Even although it costs rather mote to start with, I should retain titlo entries in all cases of fiction, and 
also in those instances where the title does not fairly readily suggest the subject heading under which it should be found. The dictionary catalogue is as susceptible of chronological indexes, fiction keys, annotations, sections and sub-sections, biographical notes, and other encyclopedic information as is the class list. I therefore claim that it does not deserve the hard words which have recently been said of it. Whether it is better than its rival, or not, may be a matter of opinion. For specialists it is not 80 good; but for ordinary students it is enough ; whilst for the general reader it appears to be decidedly superior. We are not, I take it, dealing with the reference department. There the class list may reign supreme, or share its throne with a card catalogue; but for the lending library I am of opinion that not only is there a case between them when thus compared, but that the verdict is in favour of a dictionary catalogue well carried out.

Before quitting the subject let me revert to a point raised by my predecessors. I quite agree with them that " the dates of first editions of old or epoch-making books" should be given in the catalogue. This matter has lain on my mind for a long time, and every cataloguer must have felt the absurdity of such an entry as :-

Burke (E.) Thoughts on present discontents. 1895.

A fuller entry, an explanatory note, or some indication of the original date of the work is required, so that the unwary reader may not imagine it to be an up-to-date treatise on, say, the political aspect of to-day. As this is an age of reprints the matter requires looking into.

There is also another matter which, although not strictly pertinent to the title of this paper, I desire to mention. It is that it might be advisable to include, among the numerous other appendices with which we are threatenod, a list of books of fact dealing with such persons or subjects as are treated of in notable works of fiction. The following short list will explain what I mean :-

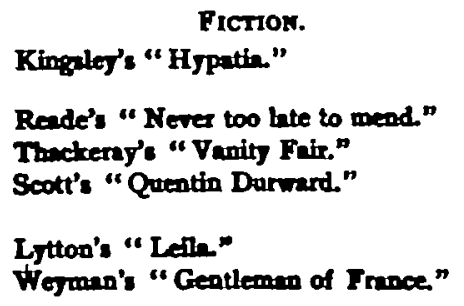

FACT.

Bradley's "Goths" (Stery of the Norions).

Hewitt's "Two years in Victorta." Eaton's "Waterloo deys" Commine's "Memoin." or other hip. tory of Lonis XI.

Irving'" "Coequeat of Grenede" Willerts " Henry of Navarre," (Browes of the Nationsl. 
It is conceivable that, especially at those libraries where a borrower may have a second (non-fictional) ticket, such a list would be appreciated by intelligent readers.

But to return. In the course of the foregoing remarks I have felt it necessary to speak plainly concerning some portions of the otherwise excellent paper on the "Compilation of the Class List." I trust that if I have got " on the warpath," as its writers suggested, I have not brandished the tomahawk too roughly. The collaboration of a paper may well result in the expression of sentiments which neither author would have written had the paper been from one pen instead of two. I expect that each left it for the other to revise and tone down certain parts ; but none the less the statements had to be challenged, or pass as gospel. We are all, I am convinced, actuated by a desire to improve what was capable of being bettered. Whether this is done in the form of class guides or by dictionary cataloguing is perhaps not of much moment. The ball has been set rolling, and something will come of it. For my own part I have honestly endeavoured to consider the pros and cons of both systems. I fear that I have inadequately dealt with the subject, but now I leave the case to the judgment of my betters with these parting words, that " much might be said on both sides."

W. E. Doubleday.

Examples of the treatment of a specific subject in a Dictionary Catalogue and in a Class List.

\section{Dictiomary Catalogue.}

Spain :-

\section{Architecture.}

Fergugson (J., D.c.L) History of architecture, vol. 2 ...

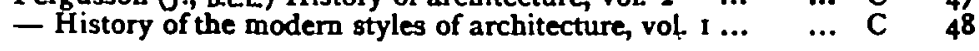

\section{Descriptive and travel.}

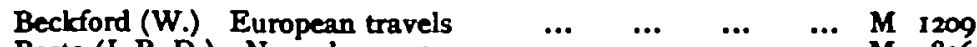

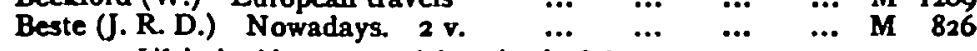

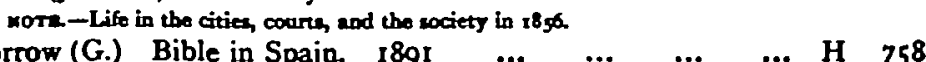

Borrow (G.) Bible in Spain. 1891 $\ldots$... $\ldots$...

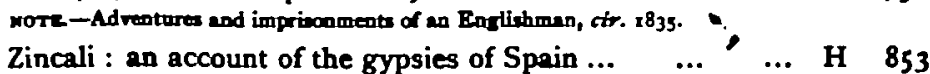

$\begin{array}{llllll}\text { - Zincali : an account of the gypsies of Spain .... } & \ldots & \ldots & \text { H } & 853 \\ \text { Clayton (J. W., carr.) Sunny south : an autumn tour. } & \text { I869 } & \ldots & \text { H } & 116\end{array}$ Corte, La: letters from Spain [in 1863-6] $\quad$... 
Debary ( $T$, nv.) Travels in the South of Spain, Algiers, and the Canary Islands [in 1849-50] $\ldots \begin{array}{llllll}\ldots & \ldots & \ldots & \ldots & \text { H } & 571\end{array}$

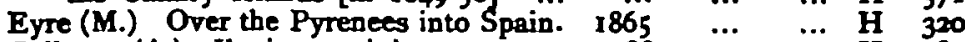

Gallenga (A) Iberian reminiscences. 2 v. 1883 ...

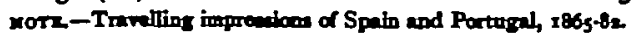

Galton (F.) Visit to North Spain in 1860 . In his Vacation

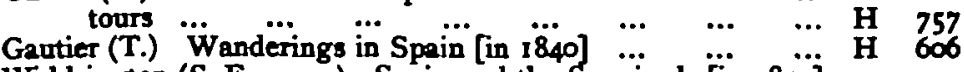

Widdrington (S. E., carr.) Spain and the Spaniards [in 1843]

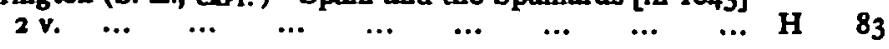

\section{Geography.}

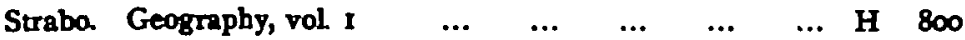

\section{History and biography.}

Dunham (S. A, 노. ) History of Spain and Portugal [218 B.C. to 1788] Lard. cab. cyclo. 5 v. ... ... … ...

Hallam, [H., L.a.) History of Spain [712-1492] In his Europe during the middle ages. $3 \mathrm{v}$. $\quad \ldots \quad$... $\quad \ldots \quad \ldots$

Henderson (R.) Soldier of three queens. $2 \mathrm{v}, \quad \ldots . \quad \ldots \quad$ H 767

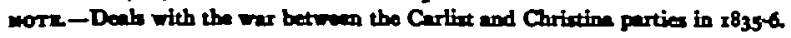

Irving (W.) Conquest of Granada, and legends of the con-

quest of Spain. In his Works, vol $5 \ldots$... Story of the
Lane-Poole (S.) Moors in Spain [711-1610]. So

Prescott (W. H.) Reign of Ferdiänd and Isabella the catholic

- History of the reign of Philip II., King of Spain [ $\dddot{\text { I } 527-80] \text { ]. }} 292$ $\begin{array}{lllllllllll}1894 & \ldots & \ldots & \ldots & \ldots & \ldots & \ldots & \ldots & \ldots & \text { H } & 293\end{array}$

Shelley (M. W.) Literary and scientific men of Spain. 3 v.... $\quad$ B 384 ron contures coox unme Biography-collective.

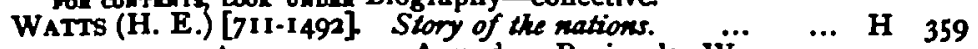

Class List.

\section{EUROPE-88-8B.}

\section{1. - Bpain, History.}

NAPIER (Sir W. F. P.) History of the war in the Peninsula. 1807-

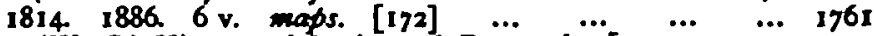
Pearce (W. C.) History of Spain and Portugal. [B.C. 2I5-A.D.

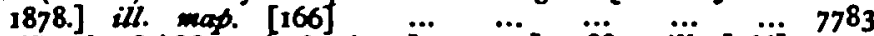
Pools (Stanley L.) Moors in Spain. [7̈55-1570] i 1387 . ili. [166] 4032 PRESCOTT (Wm. H.) History of the reign of Ferdinand and

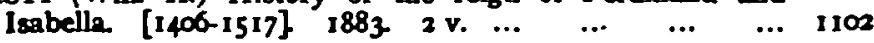
Cootation notices of Columbers atc.

WaTTs (Henry E.) Spain . . Moorish conquest to the fall of

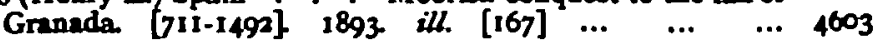

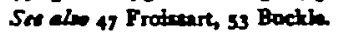




\section{Spain, Description.}

BORrow (George) Account of the Gypsies of Spain. [1835-6]. 1888 $\left[\begin{array}{lllllllll}166] & \ldots & \ldots & \ldots & \ldots & \ldots & \ldots & \ldots\end{array}\right.$

-Bible in Spain, or the journeys, etc., of an Englishman in an attempt to circulate the scriptures ... [1835-36] 1888. port. $\left[\begin{array}{llllllllll}166] & \ldots & \ldots & \ldots & \ldots & \ldots & \ldots & \ldots\end{array}\right.$

Catupion (J. S.) On foot in Spain; a walk from the Bay of Biscay to the Mediterranean. 1879 ill. [167] $\ldots$...

Chapman (Abel) and W. J. Buck Wild Spain ... . . records of sport . . natural history and exploration. 1893 .

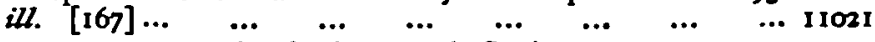
Cooteins chapters on the Gypaice.

EluJot (Frances) Diary of an idle woman in Spain. 1884 [167] 147 Travd-detches.

HarVRy (Mrs.) Cositas Españolas, or everyday life in Spain. 1875. 7442

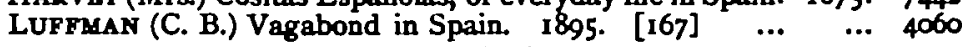
Tour in Spaln of to-dey.

O'SHRn (John A.) Romantic Spain .. . . . 1887. 2 v. [167] ... 2297 Rxperiencos and travel darting the Doo Carbos rising.

Ramsay (Mrs.) Summer in Spain. 1874 [Travel-sketches] ... 6995 Rose (Hugh J.) Among the Spanish people. 1877. 2 v.... $\quad \ldots \quad 5394$ Podetrien tour through Spain.

-Untrodden Spain and her black country _. . . 1875. 2 v.... 43t Ross (Mars) and H. Stonehewer-Cooper. Highlands of Cantsbria

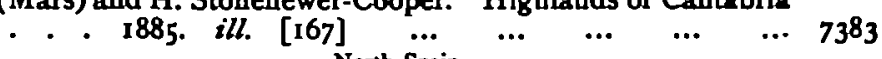

Stoddard (Chas, A.) Spanish cities, with glimpses of Gibraltar

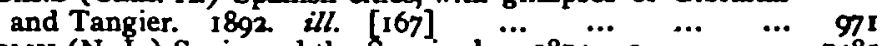

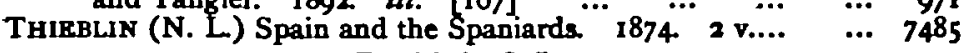
Travel during Carfint wer.

WhITE (George W.) Heart and songs of the Spanish sierras.

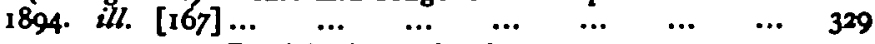
Travel skectes, mnsic and conge.
aloo 48 Blectborn, Kinguton, Werner. 